\title{
EI peso de las rupturas. El acceso a las TIC por docentes rurales y la trayectoria de la escuela
}

\author{
Recibido: 04 de agosto de 2014 \\ Aceptado: 18 de marzo de 2015 \\ Publicado: 30 de octubre de 2015
}

\author{
Edgardo Carniglia \\ ecarniglia@hum.unrc.edu.ar
}

Universidad Nacional de Río Cuarto (Argentina)

Resumen: Una perspectiva situada en el acceso a las ambivalentes TIC (tecnologías de la información y la comunicación) en el campo indica que toda transición digital implica importantes rupturas de la experiencia cotidiana. Se analiza cómo la apropiación de los dispositivos digitales por los docentes rurales instala a cierta trayectoria histórica de la escuela como una condición interviniente en la digitalización de la educación. En un entorno tecnocultural, con creciente arraigo de las TIC, estas apropiaciones suponen tensas interpenetraciones entre los atributos individuales y las condiciones contextuales del acceso a computadoras, telefonía móvil y redes. Se identifican rasgos históricos de la escuela rural y marcas de la trayectoria institucional significativos para los docentes que atraviesan la apropiación de las TIC en el aula. Los testimonios analizados corresponden a entrevistas semiestructuradas con maestros de escuelas primarias y públicas de un departamento de la provincia de Córdoba (Argentina) con una agricultura mercantil y extensiva.

Palabras clave: Acceso, TIC, escuela, maestro, ruralidad.

Abstract: A situated perspective of access to ambivalent ICT (Information and Communication Technologies) in the country indicates that any digital transition involves significant breaks of everyday experience. This text analyzes the appropriation of digital devices by rural teachers that installs a certain historical trajectory of the school as an intervener status in the digitization of education. These appropriations represent tense interpenetrations between individual attributes and contextual conditions of access to computers, mobile phones and networks in a techno-cultural environment with increasing acceptance of ICT. The fieldwork identifies historical features of the rural school and brands of the institutional trajectory significant for teachers who appropriate ICT in the classroom and the school. The analyzed testimonies correspond to semi-structured interviews with teachers in public elementary schools from a department of the province of Córdoba (Argentina) with extensive and commercial agriculture.

Key words: Access, ITC, School, Teacher, Country. 


\section{Los docentes rurales y la digitalización de la escuela}

¿Hasta dónde alcanza la digitalización en curso de la vida cotidiana? Más allá de cualquier especulación, este proceso, basado en la Internet y atravesado por el capitalismo, impresiona por su amplitud, su dinamismo y sus perspectivas de ganancias. Así lo muestran no sólo las actividades directamente ligadas a la Internet sino también hacia ámbitos tan diferentes como la industria automotriz, los servicios médicos, las finanzas y la educación (Schiller, 2014).

Dado el proceso de desarrollo desigual combinado, se genera una transición digital en la periferia capitalista en parte distinta del proceso registrado en los países centrales e incluso se observan diferencias significativas dentro de una misma sociedad periférica. Así, los heterogéneos mundos rurales argentinos (Reboratti, 2007; Reboratti y Sabalain, 2002) y los territorios de la pampa argentina también se digitalizan, acaso con una dinámica menos intensa que la registrada en los espacios urbanos.

Cecchini (2010) recuerda que en los países de América Latina y otras regiones del mundo existen distintas concepciones, en general de cuño dicotómico (Cimadevilla y Carniglia, 2009), sobre qué se entiende por urbano y rural. Así, en dicha región, los criterios censales de la ruralidad incluyen definiciones sobre el variable número de personas residentes en una cierta localidad (Argentina, Cuba y México), la cantidad de habitantes combinada con la ausencia de infraestructuras, como la pavimentación o el alumbrado eléctrico (Honduras, Nicaragua y Panamá); el número de pobladores combinado con el porcentaje de personas dedicadas a actividades secundarias (Chile), la cantidad de viviendas contiguas (Perú) y las definiciones administrativas o legales (Brasil, Colombia y otros). De este modo, en Argentina se considera como rural a toda población dispersa o aglomerada en localidades con menos de 2000 residentes.

Cualquiera sea la concepción oficial vigente sobre la ruralidad, cabe destacar que las fuentes del creciente arraigo de las TIC en unos ámbitos rurales (con histórico predominio de la oralidad) corresponden a diversos espacios de la vida social entre los que sobresalen el mercado, la escuela, los hogares y las políticas públicas. En ese sentido, cabe plantearse la siguiente interrogante: ¿Cuál es la apropiación de las ambivalentes tecnologías de la información y la comunicación (TIC) por los docentes de la escuela rural pública y primaria en este entorno sociocultural que intensifica el acceso del sistema, las instituciones y los actores educativos a la computadora, la telefonía móvil, las redes y otros dispositivos digitales?

El estudio de la digitalización de la vida cotidiana en el medio rural (con especial atención a las rupturas implicadas en la experiencia educativa) significa situarse en los bordes de la creciente informatización de diferentes actividades pues, como se dijo, acontece en un ambiente sociocultural (la ruralidad) con un histórico predominio de la oralidad como modo de comunicación. Este rasgo implica que la manifestación más intensa del proceso de digitalización acontece en los territorios urbanos provistos de mejor infraestructura y servicios informáticos y generales (Carniglia, 2012a).

En un plano de teoría general, el debate sobre el objeto de estudio tiende a concentrarse desde la segunda mitad del siglo XX en torno a la noción de "sociedad de la información" 
(Webster, 1997) que también alude a un proyecto geopolítico o en concepciones alternativas como las de "sociedad del conocimiento" o "capitalismo cognitivo". En esa línea, el mencionado autor revisa ocho propuestas sobre la sociedad de la información, concluyendo que la discusión teórica atañe a si la digitalización conforma una nueva forma de sociedad o, por el contrario, la informatización supone (como sostiene este autor) una dimensión emergente que se suma a los parámetros clásicos de la configuración social, por ejemplo el capitalismo como "clivaje sociocultural".

Si escasos estudios se conocen sobre la invisibilizada escuela rural de Argentina (Pedernera y Fiat, 2011), menos antecedentes abordan la cuestión de la apropiación de las TICS por el sistema, las instituciones y los actores de la educación ruralizada. En un estudio de alcance nacional, que cabría actualizar a la luz de las masivas políticas infoeducativas más recientes (Carniglia y otros, 2013), Magadán (2007) sostiene que, a diferencia de lo observado en el espacio urbano, los procesos de incorporación de equipamiento y conectividad digitales en las escuelas rurales argentinas hasta ahora son intermitentes y responden a diversas iniciativas del sector público, los organismos no gubernamentales y las empresas privadas. Los modos focalizados de incorporación de herramientas y redes digitales en las escuelas contemplan desde la entrega de computadoras (despojadas de contenido pedagógico y/o sensibilización previa para un uso provechoso en las aulas) hasta los programas guiados por capacitaciones intensivas para docentes y orientados al desarrollo científico-tecnológico.

Por otra parte, Fainholc (2007) ensaya una reflexión sobre la apropiación de las TIC en escuelas ruralizadas de un área peripampeana desde una perspectiva del desarrollo local dentro de la sociedad de la información o el conocimiento: propone la utilización de los medios de comunicación y las TIC, como tecnologías importadas y/o endógenas, dentro de una práctica pedagógica que prepare para la participación ciudadana y la productividad comunitaria. Finalmente, Carniglia y Tamargo (2013) analizan alcances y límites del acceso a las tecnologías digitales por docentes de escuelas secundarias públicas de espacios "rurbanos" (esto es al mismo tiempo rurales y urbanos) en el marco de la implementación inicial de una masiva política infoeducativa como el programa "Conectar Igualdad" (Carniglia y otros, 2013). Entre otras conclusiones, los autores señalan que:

- "Los rasgos demográficos de los docentes entrevistados difieren de manera significativa.

- Las condiciones laborales de estos trabajadores de la educación también varían en el caso analizado.

- Los profesores admiten la tenencia de equipamientos informáticos en el hogar y unos usos básicos de los mismos.

- Los docentes reconocen carencias importantes en la formación y la experiencia de trabajo con las TIC en el aula.

- Los responsables de la enseñanza/aprendizaje asumen tanto potencialidades cuanto riesgos de la apropiación educativa de los dispositivos digitales. 
Los profesores identifican varias condiciones facilitadoras así como diversos obstáculos de la política vigente de informática educativa que asocian con la situación de la escuela, sus colegas, los alumnos, dicha política de alcance masivo y el medio local”.

Desde este reconocimiento de las perspectivas de los formadores de la escuela pública, Carniglia y Tamargo (2013) concluyen que (mientras se profundiza la investigación sobre la apropiación de las TIC por los actores y las instituciones del sistema educativo) emerge una tesis sobre la imprescindible adaptación de las políticas y los proyectos de informática educativa a las condiciones de la escuela rurbana y sus actores como una premisa de todo proyecto de cambio social en un entorno crecientemente tecnocultural.

Nuestra investigación, en última instancia, indaga sobre la digitalización de la escuela como una experiencia sociocultural en el cruce entre lo que García Canclini (2004) denomina las "diferencias, desigualdades y desconexiones" de la apropiación de las TIC por parte de los sujetos dentro de la transición digital en curso. Las diferencias aluden, por ejemplo, a cómo atraviesan este proceso las mediaciones de edad y sexo que caracterizan a los docentes de la escuela rural. Las desigualdades se instalan, por caso, cuando en la interacción escolar las maestras se relacionan hoy con alumnos provenientes de posiciones sociales diferentes de las del docente. Las desconexiones, finalmente, se vinculan con las citadas condiciones precarias de la ruralidad respecto de las transformaciones que atraviesan la comunicación informatizada en otros territorios.

\section{EI acceso a las TIC, una perspectiva sobre la apropiación situada}

La perspectiva del acceso a las TIC se propone como una matriz conceptual que indaga simultáneamente sobre las diferentes dimensiones de una experiencia situada de apropiación de los dispositivos infodigitales por parte de distintos actores del sistema educativo a la vez que discierne criterios fundados para los proyectos y programas de desarrollo específicos (Carniglia, 2012a). Este enfoque supone una mirada comprensiva sobre dicha experiencia insinuada por Burbules y Callister (2008), entre otros intelectuales, que establecemos en un cruce entre los campos de conocimiento de la comunicación y la educación.

Una premisa teórica sostiene que (en un entorno tecnocultural y mercantilizado con creciente arraigo de las tecnologías de la información y la comunicación) las apropiaciones de la computadora, la telefonía móvil y las redes digitales por los docentes rurales de la pampa cordobesa acontecen dentro de las tensas interpenetraciones entre los atributos o posiciones individuales y las condiciones contextuales de acceso.

Nuestra perspectiva del acceso, con antecedentes germinales en los estudios de la UNESCO sobre políticas de comunicación (Servaes, 2000), comprende cinco claves analíticas:

- "Recupera un derecho reconocido en distintos marcos legales. 
- Reconoce un relativo arraigo de los dispositivos digitales en la vida cotidiana de las sociedades latinoamericanas.

- Formula un conjunto de críticas a enfoques corrientes sobre la comunicación mediada por la tecnología digital.

- Propone una serie de dimensiones analíticas de la siempre situada experiencia digital de los sujetos sociales.

- Incorpora nociones complementarias sobre las condiciones socioculturales de la apropiación de las TIC por los sujetos del campo" (Carniglia, 2012a).

Tanto en acuerdos internacionales, cuanto en pactos regionales y constituciones nacionales, se reconoce el derecho de los ciudadanos en sus facultades de investigar, recibir y difundir información (Becerra, 2003; Pautassi, 2010; Carniglia, 2014). Desde la Declaración Universal de los Derechos Humanos de las Naciones Unidas (1948) hasta las actuales Constituciones nacionales diversos documentos avalan ese derecho que, en lo posible, las políticas implementan bajo la lógica del servicio público, en el caso del espacio audiovisual, o del servicio universal, para la telefonía. Sin embargo, la retirada o el cambio de rol del Estado, luego de la avanzada neoliberal de las últimas décadas, tiende a dejar predominantemente en manos del mercado la dinámica de un área, como las de las TIC, sensible por su impacto político y cultural (Becerra, 2003; Crovi, 2008).

La emergencia y expansión de las herramientas y los servicios digitales en la vida cotidiana se vinculan tanto a las determinaciones técnicas como a numerosos procesos que contribuyen a su compleja apropiación por los actores sociales. Miège (2010) reconoce los siguientes aspectos, entre otros, del "arraigo" de las TIC en las sociedades contemporáneas:

- "La informatización o circulación creciente y acelerada de flujos de información en las esferas laboral, privada y pública.

- La mediatización de la comunicación mediante la incorporación de modalidades nuevas a un sistema de comunicación perdurable en todo el planeta.

- La ampliación de la esfera mediática en cuanto a emisores, dispositivos socio-técnicos y consumidores de nuevos y viejos medios de comunicación.

- La mercantilización de las actividades comunicacionales que enfrenta resistencias de los consumidores con limitados recursos financieros.

- La generalización de los usos de las técnicas de comunicación para administrar o gestionar ciertos espacios del funcionamiento de lo social. 
- La diferenciación de prácticas sociales de información, cultura y comunicación multisoportes, recurrentes, sustentadas en valores y asociadas a representaciones socio-simbólicas.

- La circulación de flujos y la transnacionalización de las actividades infocomunicacionales.

- La tendencia a participar en cierta forma de control social e incluso político".

Desde la perspectiva del acceso a las TIC cabe discutir los contextos, fundamentos, alcances y pertinencias (entre otros aspectos) de algunas nociones sobre la digitalización de múltiples espacios de la vida cotidiana ya instaladas en el discurso académico, político y social sobre los dispositivos info-comunicacionales. Entre estas nociones se destacan algunas quizás ya clásicas, por ejemplo "sociedad de la información" y otras más recientes, como la "sociedad del conocimiento" y la "brecha digital".

Van Dijk (2002), por ejemplo, reconoce que la popular metáfora de la "brecha" o "frontera digital" es muy exitosa para instalar la cuestión del acceso desigual a las TIC en la agenda social, política y académica pero entraña el riesgo de generar varios malentendidos. Este autor destaca algunas simplificaciones asociadas a ciertos usos de dicha concepción que distinguen insuficientemente esta nueva desigualdad de las clásicas diferencias de ingreso, educación, género, edad y etnia, entre otras. Con una orientación equivalente, García Canclini (2012) destaca, desde una perspectiva interdisciplinaria de los derechos culturales y comunicacionales, que cabe reconocer cómo se complementan y se desencuentran la diferencia cultural, la desigualdad social y la desconexión comunicacional en la construcción de la ciudadanía.

En lo atinente a la experiencia digital siempre situada de los sujetos, el enfoque del acceso a las TIC indaga sobre cuatro dimensiones analíticas:

- "Disposiciones como el interés, el atractivo y otros estados "subjetivos".

- Condiciones materiales como la tenencia o propiedad de equipos y el acceso a redes.

- Habilidades instrumentales, informacionales y estratégicas generadas por la educación, los equipos y otros apoyos sociales ${ }^{1}$.

\footnotetext{
1. Las habilidades instrumentales se relacionan con la operación de las herramientas y los servicios digitales. Las competencias informacionales aluden a la búsqueda, selección, procesamiento y aplicación de información desde una eventual superabundancia de fuentes. Las capacidades estratégicas consisten en el empleo de la información para mejorar la posición de los sujetos en la sociedad.
} 
- Usos establecidos a través de los diferentes dispositivos y aplicaciones" (Van Dijk, 2002).

Una de las incorporaciones conceptuales al enfoque del acceso a las TIC (orientada a reconocer las diversas condiciones socioculturales e históricas del entorno social) delimita más precisamente los espacios de la siempre situada experiencia de apropiación de dichos dispositivos por los sujetos rurales. Así, por ejemplo, la escuela, la unidad productiva y el hogar del campo constituyen tres ámbitos destacados y relacionados donde se concretan y proyectan los detalles contemporáneos de la apropiación de los dispositivos digitales con propósitos de cambio social (Carniglia, 2012a).

Este carácter, situado en el acceso a los dispositivos digitales, implica discriminar en la experiencia de los sujetos dos lógicas de los procesos de apropiación de las TIC en los territorios rurales: las dinámicas interpenetradas de las condiciones del contexto y las posiciones o atributos del sujeto. Por un lado, sobresalen las condiciones de contexto que enmarcan los comportamientos y las posibilidades de los actores del campo en sus relaciones con la computadora y otras tecnologías info-comunicacionales, pues establecen cierta estructura de oportunidades para el uso de los dispositivos. Estas condiciones del entorno incluyen, entre otros escenarios, a la infraestructura tecnológica disponible con un cierto grado de actualización, a la situación económica general (que define la carencia o disponibilidad de recursos para acceder a las redes) y a las políticas públicas para el acceso y la participación en las redes digitales (Crovi, 2008). Otro aspecto de estas condiciones del entorno (particularmente pertinente a la actual fase de nuestro estudio) corresponde a los rasgos del sistema educativo y de cada escuela que enmarcan los procesos de la apropiación de las TIC por los sujetos escolares.

Por otro lado, en dichos procesos de digitalización se destacan las posiciones o atributos de sujeto que dicen sobre las similitudes y las diferencias de los distintos actores rurales, por ejemplo los docentes de la escuela pública primaria, en los vínculos con los dispositivos digitales en términos de, como propone Van Dijk, (2002), sus disposiciones, condiciones materiales, habilidades y usos.

En el plano metodológico, corresponde a esta compleja perspectiva de la apropiación situada de las TIC una perspectiva general de triangulación o convergencia metodológica, entendida como una estrategia o un plan de acción de conocimiento que combina en una misma investigación varias observaciones, perspectivas teóricas, fuentes de datos y metodologías, favoreciendo su complementación (Vasilachis, 1992).

Nuestro trabajo de campo, en fase exploratoria, comprende como unidades de observación a los docentes de las escuelas rurales situadas en los bordes de la región pampeana argentina, particularmente en un departamento o distrito del sur de la provincia de Córdoba (Argentina) con predominio de una actividad agropecuaria mercantil y extensiva. Hasta el momento, hemos entrevistamos en el área a cinco maestras y a un maestro, responsables de la enseñanza en seis escuelas primarias con los rasgos señalados a continuación: 
Figura 1: Características de las escuelas rurales visitadas.

\begin{tabular}{|l|l|l|l|l|l|l|l|}
\hline Escuela & $\begin{array}{c}\text { Año } \\
\text { creación }\end{array}$ & Distancia $^{2}$ & $\begin{array}{c}\text { Edificio } \\
\text { propio }\end{array}$ & $\begin{array}{c}\text { Docentes } \\
\mathbf{( 2 0 1 3 )}\end{array}$ & $\begin{array}{c}\text { Alumnos } \\
\mathbf{( 2 0 1 3 )}\end{array}$ & $\begin{array}{c}\text { Compu- } \\
\text { tadoras }\end{array}$ & $\begin{array}{c}\text { Conexión } \\
\text { a Internet }\end{array}$ \\
\hline $\mathbf{1}$ & 1952 & 28 & Sí & 1 & 13 & 5 & No \\
\hline $\mathbf{2}$ & 1940 & 18 & Sí & 2 & 20 & 3 & No \\
\hline $\mathbf{3}$ & 1953 & 130 & Sí & 1 & 6 & 3 & Sí \\
\hline $\mathbf{4}$ & 1935 & 35 & Sí & 1 & 12 & 5 & Sí \\
\hline $\mathbf{5}$ & 1936 & 45 & Sí & 1 & 5 & 3 & No \\
\hline $\mathbf{6}$ & 1936 & 13 & Sí & 1 & 5 & 4 & No \\
\hline
\end{tabular}

Fuente: Elaboración propia.

El trabajo de campo continúa actualmente con la realización de entrevistas semiestructuradas (Flick, 2007) a otras maestras rurales y observaciones en la escuela y el aula de cada institución educativa.

Figura 2: Rasgos de los docentes rurales entrevistados.

\begin{tabular}{|c|c|c|c|c|c|c|c|c|}
\hline Docente & Sexo & $\begin{array}{l}\text { Postítulo } \\
\text { específico }\end{array}$ & $\begin{array}{c}\text { Formación } \\
\text { en TIC }\end{array}$ & $\begin{array}{c}\text { Años } \\
\text { docencia }\end{array}$ & $\begin{array}{c}\text { Años } \\
\text { escuela } \\
\text { rural }\end{array}$ & $\begin{array}{l}\text { Cargo y } \\
\text { condición }\end{array}$ & $\begin{array}{c}\text { Grados a } \\
\text { cargo }\end{array}$ & $\begin{array}{c}\text { Reside en } \\
\text { escuela }\end{array}$ \\
\hline Silvia & Mujer & Sí & No formal & 25 & 18 & $\begin{array}{l}\text { Directora } \\
\text { efectiva }\end{array}$ & $1^{\circ}$ a $6^{\circ}$ & No \\
\hline Ma. Elena & Mujer & Sí & $\begin{array}{l}\text { Formal } \\
\text { básica }\end{array}$ & 27 & 26 & $\begin{array}{l}\text { Directora } \\
\text { efectiva }\end{array}$ & $4^{\circ}$ a $6^{\circ}$ & No \\
\hline Guillermo & Varón & No & $\begin{array}{c}\text { Formal } \\
\text { aplicada }\end{array}$ & 6 & 6 & $\begin{array}{l}\text { Maestra } \\
\text { interino }\end{array}$ & $1^{\circ}$ a $6^{\circ}$ & Sí \\
\hline Claudia & Mujer & No & $\begin{array}{l}\text { Formal } \\
\text { básica }\end{array}$ & 31 & 30 & $\begin{array}{l}\text { Directora } \\
\text { efectiva }\end{array}$ & $1^{\circ}$ a $6^{\circ}$ & No \\
\hline Carolina & Mujer & No & No formal & 2 & 1 & $\begin{array}{l}\text { Maestra } \\
\text { suplente }\end{array}$ & $1^{\circ}$ a $6^{\circ}$ & No \\
\hline Adriana & Mujer & No & No formal & 24 & 21 & $\begin{array}{l}\text { Directora } \\
\text { efectiva }\end{array}$ & $\begin{array}{l}\text { Inicial, } \\
1^{\circ} \text { a } 6^{\circ}\end{array}$ & No \\
\hline
\end{tabular}

Fuente: Elaboración propia.

2. En kilómetros desde la capital del departamento provincial. 
Las expresiones analizadas a continuación provienen de los diálogos con los docentes, realizados generalmente in situ, durante los años 2012 y 2013 con las siguientes estrategias de trabajo de campo:

Figura 3: Estrategias de la entrevista semiestructurada a docentes rurales.

\begin{tabular}{|c|c|c|}
\hline & Recolección de datos & Tratamientos de datos \\
\hline Técnica & $\begin{array}{l}\text { Entrevista a docentes de una escuela } \\
\text { rural primaria. }\end{array}$ & Modalidad restitutiva y analítica ${ }^{3}$. \\
\hline Instrumento & $\begin{array}{l}\text { Guía semiestructurada con ejes } \\
\text { analíticos. }\end{array}$ & Matriz de datos cualitativos. \\
\hline Procedimiento & $\begin{array}{l}\text { Diálogo in situ (dependencias } \\
\text { escolares). }\end{array}$ & $\begin{array}{l}\text { Registro y análisis comparativo de } \\
\text { categorías y posiciones emergentes. }\end{array}$ \\
\hline
\end{tabular}

Fuente: Elaboración propia.

\section{La escuela rural, el docente/aprendiz y sus modos de apropiación de las TIC}

La presencia de las TIC en una institución educativa como la escuela rural interpela específicamente todas las dimensiones constitutivas (didáctico-pedagógica, organizacional, administrativa y comunitaria) repercutiendo en las formas de desarrollar un trabajo docente cuyo aspecto clave es la construcción de vínculos entre las nuevas generaciones de ciudadanos y los saberes relevantes para la vida en sociedad. ${ }^{3}$

Según Frigerio y otros (1992), la dimensión didáctico-pedagógica corresponde a las actividades específicas de la escuela que la distinguen de otras instituciones sociales y cuyo eje central son las relaciones que los actores construyen con el conocimiento y los modelos didácticos; la dimensión organizacional comprende el conjunto de aspectos estructurales corporizados en cada establecimiento educativo para determinar un estilo de funcionamiento; la dimensión administrativa alude a las acciones que habilitan la gobernabilidad de la escuela; y la dimensión comunitaria refiere al conjunto de actividades promotoras de la participación de los diferentes actores en las decisiones y tareas del establecimiento como también al modo en que cada institución considera las demandas, exigencias y problemas emergentes de su entorno y el contexto más global.

Es así como los docentes de las escuelas rurales (enfrentados a la digitalización de la educación y en general de la vida cotidiana) atraviesan hoy una situación intensamente paradójica: suman a su condición de enseñantes cotidianos (de diversos conocimientos

3. Con el modo restitutivo del tratamiento de los datos cualitativos se reproducen las palabras de los entrevistados casi sin mediar las interpretaciones por parte del investigador. En el modo analítico se identifican y comparan las categorías que organizan las entrevistas para arribar a estructuras de relatos comunes a los miembros de cada grupo social (Kornblit, 2004). 
y saberes) la necesidad de aprendizajes sobre dicho proceso que atraviesa su trabajo en el aula y la escuela, así como otras actividades cotidianas. En este marco, el maestro se constituye en un aprendiz en servicio atento a las exigencias de nuevos conocimientos y formas de hacer u operar, que demanda la incorporación de los dispositivos digitales. Así, por ejemplo, las maestras rurales entrevistadas en nuestro trabajo de campo reconocen que los trámites administrativos de la escuela se realizan principalmente a través del correo electrónico y otras redes digitales.

La escuela rural primaria y pública de la región pampeana de Argentina responde a un modelo acaso canónico de:

- Instituciones surgidas generalmente en un período de emergencia y relativa consolidación de la agricultura chacarera en la pampa argentina (Carniglia, 2012b).

- Pequeños establecimientos de territorios rurales, o sea con población dispersa o en pequeños conglomerados, que atienden necesidades educativas de grupos domésticos aislados.

- Matrículas de un tamaño considerado insuficiente para conformar grupos por año de escolaridad.

- Presencia generalmente de uno o pocos docentes.

- Organización particular bajo la figura del plurigrado o grados agrupados.

- Población escolar proveniente de hogares a cargo de trabajadores formales o informales activos casi todo el día y con residencia permanente en el campo.

En la figura 2 se presentan algunos rasgos de los docentes de la escuela rural (entrevistados en el trabajo de campo) que indican algunas de las principales similitudes y diferencias entre los responsables del aula en dicha institución pública. Allí se observa un absoluto predominio de las mujeres entre los docentes; una reducida proporción de las maestras con postítulo u otra formación específica para la enseñanza en escuelas rurales; las marcadas diferencias de los entrevistados en su experiencia como docentes en general y de la enseñanza rural en particular; los matices significativos en una posesión de cargos docentes asociada a la edad de los maestros; la atención por la maestra de todos los grados de la educación primaria, incluyendo el nivel inicial, o de al menos tres cursos de este nivel educativo; y la residencia de las maestras en general fuera de la escuela y en territorios urbanos distantes de la institución escolar.

Por otra parte, entre los docentes rurales entrevistados se reconocen tres modalidades no necesariamente excluyentes de aprendizaje sobre el manejo de la computadora y las redes digitales: 


\subsection{El modo no formal o no institucionalizado}

Comprende todas aquellas actividades por las cuales las maestras, a la manera de autodidactas, se apropian de las herramientas informáticas básicas por sus propios medios ya sea mediante el ensayo/error y/o apelando a sus vínculos personales extraescolares.

"Y cuando nos empezaron a exigir las cosas por computadora, igual que usar Internet, ahora todo se maneja por Internet y bueno tenés que aprender, yo tenía a mis hijos que siempre sabían un montón, entonces fui aprendiendo de ellos un montón. Si bien hice cursos, empecé varios pero nunca los terminé, pero hoy por hoy puedo defenderme, por ejemplo bajar un video con un programa y traerlo, grabar en un pendrive, lo hago. Si bien sé que me hacen falta otras cosas las estoy aprendiendo y he aprendido un montón y bueno yo ahora me busco en el Google cómo tengo que hacer para grabar tal cosa [...] $\mathrm{Si}$, si a mí me costó horrores, yo me acuerdo para escribir era como un cuco. Yo tenía una compañera mía que había hecho un curso, que ahora se fue a Villa Rosario, que había hecho un curso de computación y un día me sentó en una computadora y me dice escribí y no me preguntes, ah!!! Yo sudaba, sudaba y escribía y no sabía borrar y ella me decía buscá las teclas. Es decir uno tuvo que, yo me recibí y no existían las computadoras acá, no existían los teléfonos, no existía nada y tuvimos que aprender un montón de cosas. Yo digo a veces que soy poco inteligente, que tengo pocos fundamentos, pero uno aprendió un montón de cosas que yo no pensé nunca que las iba a aprender y menos sola" (Silvia).

\subsection{Modalidad formal básica}

Los docentes se apropian de las herramientas generales de la informática, por ejemplo programas como el procesador de texto y el generador de hojas de cálculo, pero no incursionan aún en aprendizajes sobre recursos más específicos para la educación en general y la escuela rural en particular.

"Cuando compramos la computadora para la escuela yo también me compré una, era la primera que me compraba entonces yo fui a Laboulaye, bueno primero renegué horrores yo sola, hacía lo que podía como seis meses, después fui a AIXA como un año entero así que hice como dos cursos, el primero creo que era perito, a mi me permitió manejar programas como Word, Excel, Access, un poquito de Internet, lo que pasa que yo al no tener Internet entonces tuve ese año entero. Después acá en Melo el centro tecnológico que hay en la biblioteca dio un curso de Internet porque a mí me costaba mandar los correos electrónicos y eso. Entonces sí, es que me preparé un poquito" (Claudia). 


\subsection{Modo formal aplicado}

Los docentes suman a la anterior experiencia de aprendizaje informático o al menos imaginan y demandan al respecto capacitaciones compatibles con sus condiciones de trabajo, otras experiencias con herramientas más específicas para la informatización de los procesos educativos.

"Si por lo menos mandaran una idea de cómo usar las computadoras o alguna capacitación para las docentes porque estamos abiertas a seguir capacitándonos, pero no sucede. La única experiencia que tuve sobre este tema fue un curso que hicimos con una docente sobre seguridad online donde nos explicaron los riesgos que hay cuando uno abre o utiliza una cuenta, que lo organizaba un instituto de Buenos Aires y fue realmente bueno porque aprendimos hasta a configurar nuestra cuenta de Facebook para que solo mis amigos puedan ver mis publicaciones y otras cuestiones de las que yo no tenía ni idea como cuando aparecen esas publicidades cuando uno abre Internet. Nos dieron el material para saber eliminar eso por ejemplo, nos enseñaron todos los riesgos online que puedan haber en ese taller pero nada más" (Carolina).

\section{Una dinámica trayectoria de la escuela rural}

Las características de la escuela rural constituyen una de las condiciones contextuales de la apropiación de las TIC por los sujetos escolares considerados tanto en un sentido más estricto, aquel que comprende a los docentes y alumnos como protagonistas del aula, cuanto en una perspectiva más amplia que incluye también a los miembros de la comunidad escolar (familiares de los alumnos) y el entrono rural (productores agropecuarios, trabajadores dependientes, vecinos, autoridades locales).

Al menos cinco dimensiones analíticas internas del sistema de la educación rural consideramos a priori en nuestras entrevistas y/o emergieron posteriormente en el citado trabajo de campo como relevantes para configurar el acceso situado a las TIC por los actores escolares:

- Historia de la escuela rural.

- Situación actual de la escuela.

- Relación entre la escuela y la comunidad.

- Trayectoria del docente.

- Cotidianeidad laboral.

Las tres primeras dimensiones corresponden a las condiciones de la escuela, y en particular la primera se analiza en el presente artículo, mientras que las dos restantes aluden a la situación del docente. Una regla general establecería que la trayectoria de estos establecimientos educativos públicos sucede atravesada por los acontecimientos y procesos de la historia agraria local inseparables a su vez de la historia rural pampeana y argentina. 
Como se aprecia en la figura 1, las seis escuelas rurales visitadas en el comienzo de nuestro trabajo de campo fueron creadas entre 1935 y 1953. Este período de creación corresponde a una fase de emergencia y relativa consolidación en la pampa argentina de la agricultura chacarera, aquella del trabajo y la residencia en el campo de los miembros de las explotaciones familiares. Tras la incorporación de Argentina a los circuitos mundiales de acumulación capitalista bajo un régimen agroexportador (entre 1880 y 1930) la estructura agraria basada en el predominio del vínculo entre estancieros y colonos se transformó desde aproximadamente el último año citado, con la emergencia de una nueva categoría social agraria (el chacarero) que logró acceder a la propiedad de la tierra mejorando así sus posibilidades relativas de decidir qué y cómo producir al tiempo que se facilitó la residencia más estable de su grupo doméstico en el campo (Carniglia, 2012b).

Este atravesamiento de la escuela rural por las circunstancias históricas de la pampa argentina es asumido por los docentes entrevistados desde diversas expresiones:

“Acá al lado funcionaba una fábrica. Entonces los padres traían la leche porque había una fábrica de queso que se llamaba Cooperativa Tambera de las Tres Colonias Unidas. Y bueno entonces los padres traían la leche y estaban los chicos y los esperaban porque venían en carro, eso es lo que me han contado de esa época. Esta era una zona totalmente tambera, había entre cuarenta y cincuenta tambos, y estaba toda la gente y realmente era una colonia, una gran colonia [...] después con las inundaciones, la siembra directa, los tambos que se fueron cerrando y bueno esto se convirtió en lo que es hoy, en una zona netamente agrícola y quedan muy pocos tambos, muy pocos tambos quedaron. Habrán quedado seis, siete tambos en toda la zona" (Silvia).

"En cuanto a lo que se mantiene es una zona tambera, casi exclusivamente, si bien se siembra y hay ganado, pero es tambera. Eso se mantiene siempre, porque tenemos una población que va cambiando, decimos eso porque los tamberos van y vienen, ese tipo de gente a veces está un año, a veces menos o hay tamberos que tenemos hace muchos años y hay gente, hay algunos propietarios, que están desde que yo estoy. Esa gente está todavía, van cambiando los empleados pero los propietarios se mantienen" (María Elena).

Estos testimonios de las maestras reconocen en primer lugar una reorientación de la producción agropecuaria hacia producciones menos intensivas en fuerza de trabajo local, en general actividades agrícolas antes que mixtas, que es contemporánea de la avanzada migración rural-urbana de los antiguos habitantes del campo y de una transformación cualitativa de la población de los hogares rurales con trabajadores dependientes. En este sentido, cabe consignar que en el departamento o distrito del trabajo de campo de este estudio la población rural dispersa o aglomerada no supera actualmente una cuarta parte de la población total del área. 
Por otra parte, las maestras rurales tematizan en los siguientes términos la creación de la escuela rural en la fase de consolidación de las explotaciones familiares en la pampa cordobesa:

"Esta escuela fue creada en el año 1952, tiene sesenta años la escuela y bueno en sus inicios la matrícula era de sesenta alumnos, sesenta y cinco, setenta alumnos, de todas las edades, había alumnos de diecisiete, dieciocho años, que han venido a aprender a leer y escribir [...] Había una maestra que vivía acá, era de Córdoba [...] tenía los alumnos los más pequeños a la mañana y los más grandes a la tarde" (Silvia).

"La escuela el año que viene va a cumplir 60 años, sesenta años que dentro de la estancia dejó de ser una comisaría, se habrán dado cuenta del detalle que está toda enrejada la escuelita, y la escuela funcionó, por los documentos que he leído para la presentación del año que viene, desde 1953, un 16 de junio que dejó de funcionar como comisaría; el edificio estuvo un tiempo sin usarse y después de abrió la escuela pero la escuelita ya funcionaba en lo que hoy se ve acá enfrente un galpón. Me lo contó un papá, la escuela funcionaba en un principio en dos edificios tanto acá como en los salones del galpón por la cantidad de matrícula que había. La escuela se fue adaptando y luego de cerrar la comisaría se ins taló acá la escuela" (Guillermo).

De este modo, la condición de unas escuelas rurales creadas hace cinco o más décadas (figura 1), los antecedentes de una matrícula de alumnos mucho mayor que la actual y el trabajo en un edificio escolar reciclado de otras agencias estatales constituyen marcas de la trayectoria institucional de las escuelas reconocidas también por sus docentes contemporáneos. Asimismo, la relación con la comunidad, por ejemplo a través de la cesión del terreno y/o la construcción del edificio representa un rasgo emergente en la creación o etapa fundacional de las escuelas rurales de la pampa cordobesa. En ocasiones, esta situación implicaba una convergencia entre el estado y los propietarios agrarios que sumaban sus recursos para dar forma a dicha institución educativa que atendía las demandas educacionales del territorio local:

"Esta escuela se llama Emilio Alejandro Carballeira, un doctor, médico de Rufino y dueño de la estancia [...] un doctor muy importante de su época fue, que ha hecho cosas por el pueblo según tengo entendido y hoy en día no he conocido a la dueña de la estancia que vendría a ser hija del doctor, es una señora grande ya; la he conocido de chico pero desde otras instancias, no desde lo educativo, o sea, no como director de la escuela en su estancia, digo su estancia porque la escuela está en un terreno cedido por el doctor, no es una escuela con terreno propio y muchas cosas dependen de la estancia. El trato con la dueña es muy bueno y con los empleados pero la dueña, la señora Elvira, es una señora mayor por lo que no puede acercarse a la escuela, pero el anteaño pasado ha venido al acto de fin de ciclo, siempre estuvo a disposición de la escuela" (Guillermo).

En este sentido, los maestros con más experiencia entrevistados en nuestro trabajo de 
campo y/o los pobladores más antiguos de la zona recuerdan que la mayor población del campo en la etapa chacarera de la pampa argentina (1930-1969) implicó, según se dijo, una muy significativa matrícula para las primeras décadas de la escuela rural pública:

"Había mucha gente acá, hubo hasta cerca de cuarenta alumnos hace treinta años atrás, si había una matrícula grande pero bueno. Y siempre vivieron los maestros acá en la escuela excepto hasta quince años atrás hará, hasta ahora que volvimos. Pero si no iban y venían maestras, que algunas ni eran de la provincia de Córdoba porque a veces venían de Santa Fe por el tema de las distancias" (Guillermo).

"Por lo que me cuentan, la escuela en algún momento ha sido muy grande. Es una zona de productores importantes, había dos tambos muy importantes en la zona entonces, había muchísimas familias con chicos para trabajar con empleados y en esos tiempos vivían en los campos y se establecían acá. Entonces es una escuela con una estructura y un edificio grande y se necesitaban dos aulas porque eran cuarenta y ocho, cuarenta. Ese era el número de alumnos que se manejaban. Eran dos docentes en el establecimiento una como directora y la otra como maestra de grado, a su vez la directora también tenía un grado a cargo por la cantidad de alumnos" (Carolina).

Estos testimonios de los actuales docentes rurales cordobeses insinúan que el mayor tamaño de la matrícula en sus escuelas se asoció a una más amplia proporción de población rural en el territorio regional. Una significativa reducción del número de explotaciones agropecuarias, en general de las más pequeñas en superficie y a cargo de agricultores familiares, subyació al despoblamiento del campo de la pampa cordobesa: en el año 2002 el departamento Roque Sáenz Peña, el área de las escuelas relevadas en nuestro trabajo de campo, contaba con 749, o sea sólo un 45\%, de sus 1653 unidades productivas censadas en 1969 (Carniglia, 2012b).

De este modo, en los últimos años, la matrícula de la escuela rural pública y primaria disminuyó en proporciones significativas, al tiempo que el espacio rural de la pampa cordobesa se despoblaba de gente casi de manera constante. Las siguientes expresiones destacan lo también señalado en la figura 1, respecto de que hoy estudian en estas escuelas del campo un promedio aproximado a la docena de alumnos:

"Nosotros teníamos desde que yo comencé, hace treinta años atrás, veinticuatro, veinticinco, treinta alumnos. Yo cuando empecé estaba sola con veintiséis alumnos y ahí pusieron a otra maestra, a los pocos años crearon otro cargo. Cuando sacaron el séptimo grado, que se fueron los de séptimo y los de sexto también se fueron algunos de otros grados porque las mamás se fueron a vivir a Laboulaye para acompañar a esos de sexto grado que eran muy chicos. Entonces tenían a chicos por ejemplo en tercer grado que también se fueron, no tengo presente en qué año se sacó el sexto, perdón el séptimo, y ahí se disminuyó muchísimo la matrícula. Y cuando tuvimos inundaciones también, hubo momentos en que tuvimos once alumnos, ocho alumnos y seguíamos siendo dos docentes, también mi compañera 
estuvo de licencia y en tareas pasivas, por eso creo que seguimos siendo las dos, es decir seguimos estando en el cargo porque ella está con tareas pasivas, licencias, varios años estuvo así, entonces bueno ella no trabajaba y trabajaba yo. Bueno, las inundaciones nos afectaron mucho y ahora, como se recuperaron bastante los campos y algunos tambos siguen firmes, la matrícula se mantiene. Pero yo, haciendo un censo proyectivo a cinco años que es lo que nos hacen hacer, no supero los quince, doce, trece, alumnos. Nunca con riesgos de que la escuela se quede sin alumnos, pero no podemos superar los once o trece alumnos" (Claudia).

"La matrícula ronda entre cinco alumnos a nueve alumnos más o menos, es bastante inestable porque depende de las migraciones y de las familias si se van o llegan por trabajo, que por ahí vienen por cambio de trabajo y otros se van por algún ofrecimiento, son bastante golondrinas las familias" (Adriana).

Sin embargo, este espacio casi vaciado de pobladores, no pierde las relaciones sociales agrarias subyacentes, por ejemplo el histórico predominio de las grandes explotaciones agropecuarias en el control de la tierra y otros recursos productivos. Así, los censos agropecuarios mostrarían que la cantidad de explotaciones pampeanas de 500 o menos hectáreas se ha reducido en al menos una cuarta parte desde el año 1998 hasta la actualidad (Carniglia 2012b). Cabe así establecer, como regla general, que la cantidad de alumnos de estas escuelas rurales públicas depende generalmente del tamaño de la población rural que ha disminuido muy significativamente en las últimas décadas.

Este despoblamiento del campo (con la consiguiente pérdida de matrícula de la escuela rural) se asocia, a su vez, con una modalidad agroproductiva extensiva, cuya modernización implicó una baja demanda de trabajo permanente, en lo que Lattuada y Neiman (2005) consideran un proceso de crecimiento de la producción agropecuaria con exclusión social. En consecuencia, las maestras más experimentadas recuerdan como varias de las anteriores extensivas explotaciones agrícola-ganaderas y tamberas o lecheras se transformaron, y aún se convierten, en unidades agrícolas también extensivas con un predominio del cultivo de soja y una menor dotación de fuerza de trabajo agropecuaria:

"Generalmente lo que da mayor población es la explotación tambera y parte la ganadera más que la agrícola porque con los que siembran soja no queda nadie, porque no les hace falta. Si no dejan alguna persona grande, o buscan que la persona sea grande, sin hijos" (María Elena).

"En las cercanías de la escuela hay ganadería poca pero hay, hay más agricultura porque acá alrededor, ¿qué tenemos? Claudina y Los Médanos que no se si tienen animales, es poca la ganadería, es casi todo agricultura; y por eso la matrícula tan baja porque hoy en día si no hay ganado ni una familia que lo cuide o que haga el tambo ni que viva en el campo. En esta estancia misma tenemos dos peones que trabajan y, si hubiera ganado, serían los encargados porque podrían cuidar los animales y estar con su familia pero bueno..." (Guillermo). 
“En qué trabajan las familias de los alumnos? Casi todos, digamos hay uno solo que es productor y dueño del campo donde está viviendo, los demás son empleados relacionados con tambos. Algunos son propiamente tamberos, otros son empleados en la crianza de los terneros en el tambo. Ahora los tambos están tan organizados ya que uno es el tambero, el otro cría los terneros, otro es encargado de la comida para los animales y ellos le dicen el mixero que es el que prepara, muele y reparte toda la comida. Entonces hay gente que es tambera, hay gente que está para la crianza de los animales y hay otros que están para el preparado de los alimentos. Y después hay otro que es empleado rural que bueno por su cuenta cría cerdos y así. Pero te digo el hecho de que subsistan tambos es lo que ayuda a que la escuela se mantenga porque hay una escuelita acá cerca que se cerró, la escuelita de El Guanaco. A nosotros nos está ayudando mucho el tema de los tambos" (Claudia).

"Hay tambos ahora, pero mi escuela se inserta en una zona agrícola-ganadera y en la ganadería no hay tambos, ahora hay un tambito de un señor que es pequeño porque el señor hace mozzarella pero también crían chanchos y hay otra producción menor para subsistencia familiar porque los padres, aparte de ser empleados de campo, desarrollan su propio circuito productivo que es de subsistencia familiar, pero lo macro es la agricultura y la ganadería" (Adriana).

Finalmente, la escuela rural también supone para sus sujetos una relación más intensa o menos mediada con su medio ambiente, con la consiguiente mayor exposición a los riesgos de esta situación. Un incidente importante (por su intensidad y reiteración) marca la trayectoria de la escuela rural en este espacio sureño de la pampa cordobesa con limitaciones agroecológicas: la inundación de una muy amplia proporción del territorio de nuestro trabajo de campo, que incluso afectó a algunos núcleos urbanos. Las maestras no olvidan aún los más problemáticos o críticos anegamientos de las últimas décadas, acontecidos en la transición entre los siglos XX y XXI, que interrumpieron o transformaron de manera significativa sus rutinas de trabajo:

"En el año noventa y ocho, después estuvo lo de las inundaciones en el noventa y nueve y en el dos mil uno también hubo inundaciones que afectó; por eso la escuela estuvo cerrada, trasladaban las escuelas a campos vecinos, había que pasar en sulky por medio de los campos porque estaba todo lleno de agua y bueno la escuela se pudo mantener por la acción de los docentes, junto con la otra compañera nunca la dejamos a la escuela, pudimos haber dicho nos vamos, pero no quisimos. Los inspectores nos decían déjenla, las reubicamos, pero yo nunca me quise ir de esta escuela. Entonces siempre insistimos, buscamos a los chicos, fuimos a otro lugar, sacamos las cosas porque teníamos el agua a la cintura. Esta escuela tuvo hasta tres, cuatro centímetros el agua adentro, en todo el patio y bueno algunas cosas las dejamos otras las sacamos con carros a caballo, hemos hecho mucho sacrificio para que la escuela hoy esté como está” (Silvia). 
"Se inundó. Sí, en el noventa y nueve y en el dos mil uno, en el noventa y nueve era la ruta, nosotros no podíamos pasar por la ruta, porque una parte de la ruta cuatro, no sé si la conocés, bueno también por la cantidad de lluvia se había tapado parte de la ruta. Entonces pasábamos como podíamos, y para volver, en esa época yo ya estaba con la compañera que estoy ahora y a veces charlamos y decíamos 'yo si tuviera que hacer otra vez eso, no lo haría más ahora'; porque íbamos en colectivo en la escuela y el colectivo iba por la ruta y en un momento la ruta se convertía en una laguna, todos los campos, decí que la ruta era recta y el colectivo iba, yo iba agarrada porque se movía, había pozos. Por ahí nos quedábamos en el medio del agua porque venía uno de frente y ah!!! Yo me acuerdo que ese año terminé y se me subió el colesterol, me influyó en la salud [...] Porque claro pasaba unos nervios, era una cosa que era [...] Bueno después lo arreglaron, vino De la Sota y estaba todo bien. Después, en el dos mil uno se inundó toda la parte del puente, no se podía pasar, entonces la forma de pasar era con los bomberos, nos pasaban los bomberos en lancha, había que pasar ese pedacito en lancha, porque estaba llena de agua la parte del puente, si no había otro camino y también era muy complicado porque las napas estaban altas y, al pasar tantos camiones que no podían pasar por ahí, estaba lleno de baches. Entonces había que pasar en lancha y del otro lado nos esperaban los papás en tractor y de ahí nos llevaban a la escuela" (María Elena).

"Yo con las inundaciones sufrí mucho de ver la escuela toda inundada y teniendo hasta la política en contra porque la provincia estaba gobernada por el señor Mestre que decía que si las maestras no estaban en las escuelas, se cerraban las escuelas. Y las maestras no estaban porque había agua en las aulas y las familias tuvieron que irse, pero nosotras nos quedamos aunque fuera a la orilla de la ruta. Íbamos todos los días a trabajar y si hoy lo tuviera que hacer no lo haría nuevamente porque estuve con neumonía de la que no me podía recuperar porque ni licencia teníamos" (Adriana).

Estas expresiones de los docentes más experimentados destacan la magnitud de las recurrentes inundaciones del territorio inmediato de las escuelas rurales, que son enfrentadas principalmente desde un compromiso de las maestras con su institución educativa, acompañado por el apoyo de otras instituciones o miembros individuales de la comunidad local.

\section{Una transición digital como ruptura y la historia de la escuela rural pampeana}

Los heterogéneos mundos rurales argentinos, por ejemplo los territorios de la pampa argentina, también se digitalizan acaso con una dinámica menos intensa que la registrada en los espacios urbanos. Las fuentes del arraigo de las TIC en estos ámbitos con histórico 
predominio de la oralidad corresponden a diversos ámbitos de la vida social entre los que sobresalen el mercado, la escuela, los hogares y las políticas públicas.

La digitalización de la educación como ruptura alcanzaría ya a las cuatro dimensiones constitutivas de la escuela rural (didáctico-pedagógica, organizacional, administrativa y comunitaria) repercutiendo en los modos de un trabajo docente, cuya clave es la construcción de vínculos entre las nuevas generaciones de ciudadanos y los saberes relevantes para la vida en sociedad. Sin embargo, esta digitalización de la escuela no adquiere una similar intensidad en dichas dimensiones porque hasta ahora predominaría la informatización de las actividades administrativas.

A su vez, la digitalización implica también para el docente rural la ruptura de su excluyente condición de enseñante porque la emergente apropiación educativa de la computadora, la telefonía móvil y las redes informáticas instalan la demanda de aprender sobre su uso en la dimensión didáctico-pedagógica del aula. En este sentido, las maestras reconocen diferentes modos de aprendizaje respecto de las TIC al tiempo que demandan capacitaciones adaptadas a sus condiciones de trabajo. Enfrentados a una transición (aquella por la cual se digitalizan al menos parcialmente la comunicación, la educación y otras experiencias de su vida cotidiana) las maestras y, en alguna situación puntual, los maestros de la escuela rural viven la apropiación de las tecnologías digitales atravesados también por otras transiciones como procesos de cambio social.

Entre estos movimientos, se destacan las dinámicas del espacio agrario pampeano cuya agricultura se tecnifica y concentra bajo un modelo de agronegocio que profundiza el vaciamiento del campo de sujetos rurales pero no de relaciones sociales. De este modo, ante la merma pronunciada de la matrícula, la escuela primaria pública del sur de Córdoba enfrenta en varias situaciones el fantasma de su clausura temporaria o el cierre definitivo. Otra transición actual de la escuela primaria y pública emerge de su trayectoria histórica que constituye también una de las condiciones de contexto de apropiación de las TIC por los sujetos de la educación.

Así, según indican los testimonios de maestras y maestros, la escuela rural del área de nuestro estudio se despliega en el siglo XXI en el cruce entre: a) la continuidad o reproducción de algunos de sus rasgos históricos, como la modalidad del plurigrado que atiende a una población rural dispersa o de pequeños conglomerados; $b$ ) una significativa reducción de la cantidad de alumnos, originada en un despoblamiento del campo derivado del predominio de la agricultura extensiva, basada en la producción de soja, así como la transformación cualitativa de la matrícula asociada a los cambios del trabajo agropecuario; y c) una intensa relación con el entorno ambiental y comunitario que también instalan marcas o huellas significativas para la compleja y dinámica trayectoria de la escuela rural pampeana.

Así, tanto estas condiciones históricas de la escuela rural cuanto la digitalización de la educación operan como rupturas significativas para el trabajo de maestras y maestros de los diversos territorios rurales de Argentina y, en particular, de la región pampeana, cuyo reconocimiento en detalle demanda la continuidad de estudios sobre la apropiación de las siempre ambivalentes 
TIC (Feenberg, 2012) por los actores, las instituciones y el sistema de la educación rural. Cabe, finalmente, asumir los rasgos históricos de la escuela rural del sur de Córdoba como unas específicas condiciones del contexto sociocultural, entre otras, para las intervenciones estatales o particulares que atiendan a la profunda brecha digital de unas instituciones educativas públicas sin atajos ante el desafío de una educación de calidad, inclusiva y democrática que habilite también para la ambivalente digitalización de la vida cotidiana.

\section{Fuentes consultadas}

Becerra, M. (2003). Sociedad de la información. Proyecto, convergencia, divergencia. Buenos Aires: Norma.

Burbules, N. y Callister, T. (2008). Educación: riesgos y promesas de las nuevas tecnologías de la información. Buenos Aires: Granica.

Carniglia, E.

_(2014). "Comunicación para el desarrollo como derecho humano: el acceso a las TIC en el mundo rural”. XII Congreso ALAIC - Grupo Comunicación, Tecnología y Desarrollo. Lima, Perú.

_(2012a). "Las TIC en el campo moderno. Los espacios críticos de la comunicación rural", pp. 419-439. En Fagundes, D. y Cimadevilla, G. Caminhos do campo comunicacional no Brasil e na Argentina. San Pablo: INTERCOM.

_(2012b). De labradores y campos de papel. Recepción de prensa agraria por agricultores familiares. Saarbrücken: Editorial Académica Española.

Carniglia, E. y Tamargo, C. (2013). “Antes del aluvión. Los formadores de una escuela rurbana en la transición digital”. Congreso ENACOM. Río Cuarto, Argentina.

Carniglia, E. y otros (2013). Entre politicas, aulas y hogares. Dilemas de la informática educativa pública. Buenos Aires: Dunken.

Cecchini, S. (2010). "Indicadores sociales y derechos humanos: algunas reflexiones conceptuales y metodológicas", pp. 89-126. En Abramovich, V. y Pautassi, L. (comps.). La medición de derechos en las políticas sociales. Buenos Aires: Del Puerto.

Cimadevilla, G. y Carniglia, E. (comps.) (2009). Relatos sobre la rurbanidad. Río Cuarto: UNRC.

Crovi, D. (2008). “Dimensión social del acceso, uso y apropiación de las TIC”. Contratexto, núm. 16, pp. 57-66.

Fainholc, B. (2007). "El papel del desarrollo comunitario local en la sociedad de la información y el aporte de las tecnologías de la información y la comunicación", pp. 115-135. En Castillo, S. (dir.). Escuelas ruralizadas y desarrollo regional. Lecturas pedagógicas. Buenos Aires: UNLP. 
Feenberg, A. (2012). Transformar la tecnología. Una nueva visita a la teoría crítica. Bernal: Universidad Nacional de Quilmes.

Flick, U. (2007). Introducción a la investigación cualitativa. Morata: Madrid.

Frigerio, G. y otros (1992). Las instituciones educativas. Cara y Ceca. Buenos Aires: Troquel. Garcia Canclini, N.

_(2012). "Introducción: comunicación y derechos humanos", pp. 17-28. En Vega Montiel, A. (coord.). Comunicación y derechos humanos, México D. F.: UNAM, CIICH, AIECS. _(2004). Diferentes, desiguales y desconectados. Mapas de la interculturalidad. Barcelona: Gedisa.

Kornblit, A. (comp.) (2004). Metodologías cualitativas en ciencias sociales. Modelos y procedimientos de análisis. Buenos Aires: Biblos.

Lattuada, M. y Neiman, G. (2005). El campo argentino. Crecimiento con exclusión. Buenos Aires: Capital Intelectual.

Magadán, C. (2007). "Las tecnologías de la información y la comunicación (TIC) en las escuelas rurales de la Argentina”, pp. 105-122. En AA. VV. Las TIC: del aula a la agenda política. Buenos Aires: UNICEF.

Miège, B. (2010). “1. La cuestión de las TIC: hacia nuevos planteamientos”, pp. 15-44. En Moraes, D. Mutaciones de lo visible. Comunicación y procesos culturales en la era digital. Buenos Aires: Paidós.

Pautassi, L. (2010). "Indicadores en materia de derechos económicos, sociales y culturales. Más allá de la medición”, pp. 1-88. En Abramovich, V. y Pautassi, L. (comps.). La medición de derechos en las políticas sociales. Buenos Aires: Del Puerto.

Pedernera, A. y Fiat, F. (2011). El docente rural. Prácticas de enseñanza en el plurigrado. Buenos Aires: De los cuatro vientos.

Plencovich, M. y otros (2008). La educación agropecuaria en la Argentina. Génesis y estructura. Buenos Aires: CICCUS.

Reboratti, C. (2007). "Los mundos rurales", pp. 85-108. En Torrado, S. (comp.). Población y bienestar en la Argentina del primero al segundo centenario. Una historia social del siglo $X X$ [vol. II]. Buenos Aires: Edhasa.

Reboratti, C. y Sabalain, C. (2002). "El mundo rural de Argentina”, pp. 23-62. En Segrelles, S. (coord.). Agricultura y espacio rural en Latinoamérica y España. Posibilidades y riesgos ante la mundialización de la economía. Madrid: MAPA.

Schiller, D. (2014). "El imperio del capitalismo digital". Le Monde diplomatique, pp. 10-12. 
Servaes, J. (2000). "Comunicación para el desarrollo: tres paradigmas, dos modelos". Temas y Problemas de Comunicación. Año 8, vol. 10, pp. 5-28.

Van Dijk, T. (2002). “A framework for digital divide research”. Extraída el 22/VII/2015 desde http://www.utwente.nl/bms/mco/bestanden/digitaldivide.pdf

Vasilachis, I. (1992). Métodos cualitativos I. Los problemas teórico-epistemológicos. Buenos Aires: CEAL.

Webster, F. (1997). Theories of the information society. Londres: Routledge. 